\title{
ANALISA POTENSI DAN PENGETAHUAN KARYAWAN RUMAH SAKIT SYAFIRA TERHADAP ZAKAT PENGHASILAN
}

\author{
Rizalul Fikri $^{1}$ Budi Trianto $^{2}$ Ade Chandra ${ }^{3}$ \\ ${ }^{* 1,2}$ \&3 Sekolah Tinggi Ekonomi Islam Iqra Annisa Pekanbaru \\ Jl. Riau Ujung No.73, Tampan, Kec. Payung Sekaki, Kota Pekanbaru, Riau 28291 \\ e-mail: : rizalulfikri654@gmail.com; adec152@gmail.com
}

\begin{abstract}
Abstrak: Penelitian ini bertujuan untuk mengetahui pengetahuan karyawan Rumah Sakit Syafira terhadap zakat penghasilan dan mengetahui penghasilan yang waj ib atau yang telah mencapai nisabnya untuk membayar zakat. Penelitian ini merupakan penelitian lapangan(Field Reseach), dengan pengumpulan data secara langsung melalui kuesioner, wawancara dan dokumentasi. Populasi dalam penelitian ini adalah para karyawan yang bekerja di Rumah Sakit Syafira Pekanbaru. Responden dari penelitian ini sebanyak 158 orang, sedangkan jumlah populasi dalam penelitian ini adalah 260. Berdasarkan hasil penelitian di lapangan dapat dikemukakan bahwa hasil penelitian membuktikan bahwa variabel knowledge (pengetahuan) karyawan terhadap zakat penghasilan dibilang cukup, karena kurangnya sosialisasi tentang zakat penghasilan di Rumah Sakit Syafira dan hasil penelitian membuktikan bahwa variabel potency (potensi) zakat di Rumah Sakit Syafira dengan total Rp. 12.000.000 juta, bisa dikatakan cukup baik. Penelitian ini ditujukan untuk para karyawan di Rumah Sakit Syafira Pekanbaru agar para karyawan mengetahui zakat penghasilan dan para pembaca lainnya untuk bahan referansi kedepannya.
\end{abstract}

Kata Kunci: Rumah Sakit, Zakat, Pengetahuan dan Potensi. 


\section{PENDAHULUAN}

Zakat merupakan rukun Islam yang ke empat yang mana selalu dipandang sebelah mata yang mana kita tahu zakat sangat penting dan wajib bagi yang sudah mencapai nisab (jumlah batasan kepemilikan seseorang). Disisi lain zakat sebagai bentuk sosial dalam bentuk tolong menolong yang mana saling mensejahterakan sesama umat guna menaikkan ekonomi umat Muslim. Dalam ekonomi Islam pertumbuhan ekonomi itu sangat penting dan juga membantu antar pembeli dan penjual dan juga menaikkan ekonomi umat. Bila dilihat dari jenis zakat yang ada saat ini yaitu: Zakat Fitrah adalah zakat yang wajib dikeluarkan Muslim menjelang Idul Fitri pada bulan suci Ramadhan besar zakat ini setara dengan 3,5 liter (2,7 kilogram) makanan pokok yang ada di daerah bersangkutan seperti beras, gandum dan sejenisnya, Zakat Maal (Harta) adalah yang wajib dikeluarkan seorang muslim sesuai dengan nishab dan haulnya. Waktu pengeluaran zakat jenis ini tidak dibatasi jadi bisa dikeluarkan sepanjang tahun ketika syarat zakat terpenuhi tidak seperti zakat fitrah yang hanya dikeluarkan ketika ramadhan. Dari kesimpulan harta ada beberapa lagi yaitu : zakat penghasilan, zakat pertanian, zakat perniagaan.

Selain suatu kewajiban bagi umat Islam, melalui zakat, Al-Qur'an menjadikan suatu tanggung jawab bagi umat Islam untuk tolong-menolong antar sesama. Dalam kewajiban zakat, terkandung unsur moral, sosial dan ekonomi, dalam bidang moral, zakat mengikis habis ketamakan dan keserakahan orang kaya, menyucikan jiwa orang yang menunaikannya dari sifat kikir, menyucikan dan mengembangkan harta miliknya. Walaupun secara zhahir harta muzzaki berkurang jumlahnya.

Namun, secara hakikatnya harta tersebut berkembang dan akan bertambah keberkahannya. Zakat menupakan manifestasi rasa syukur atas nikmat Allah. Allah dalam firman telah menjanjikan akan melipatgandakan nikmatnya bagi siapa saja yang menyerahkan sebagian hartanya kepada orang lain dengan penuh keimanan dan keikhlasan (Rozalinda, 2016 : 248).

Penerapan zakat akan membuat permintaan investasi untuk setiap expected rate of return akan selalu lebih tinggi dalam perekonomian Islam dibandingkan perekonomian konvensional. Hal ini terjadi karena dalam perekonomian Islam meminjamkan modal untuk mendapatkan bunga adalah dilarang, sehingga alternatif bagi investasi rill hanyalah membiarkan modal menganggur. Namun modal yang mengaggur ini akan terkena penalty zakat. Dengan demikian, dalam perekonomian Islam, opportunity cost dari tidak menginvestasikan aset menganggur adalah tarif zakat dikalikan aset yang menganggur tersebut, bukan nol sebagaimana di perekonomian konvensional.

$$
\text { Karena zakat terhadap }
$$
keseluruhan kekayaan, tidak hanya terhadap pendapatan, maka selain mempenalti harta yang menganggur, zakat juga secara otomatis mempenalti penggunaan sumber daya di aset-aset yang tidak produktif dan tidak berkembang seperti perhiasan emasperak, dan property mewah. Dengan demikian, dalam perekonomian Islam dimana zakat diterapkan, akan terjadi investment-switching dari investasi di aset-aset yang tidak produktif ke investasi di aset-aset produktif. Sementara itu, sebagai sistem perpajakan, zakat adalah sistem pajak yang ramah terhadap dunia usaha sehingga diayakini akan berdampak positif pada produksi agregat. Zakat memiliki tarif yang rendah dan tetap serta tidak pernah berubah-ubah karena sudah diatur dalam syariah. 
Misalnya, zakat yang diterapkan pada basis yang luas seperti zakat perdagangan, tarif hanya 2,5\%. Ketentuan tarif zakat ini tidak dapat diubah oleh siapa pun. Karena itu penerapan zakat tidak akan mengganggu insentif investasi dan produksi, serta memberikan kepastian usaha.

Zakat juga memiliki tarif berbeda untuk jenis harta yang berbeda, dan mengizinkan keringanan bagi usaha yang memiliki tingkat kesulitan produksi lebih tinggi. Sebagai misal, zakat untuk produk pertanian yang dihasilkan dari lahan irigasi tarifnya adalah 5\%, sedangkan jika dihasilkan dari lahan tadah hujan tarifnya $10 \%$. Tarif zakat barang tambang bervariasi antara 2,5\%, 5\%, 10\%, dan $20 \%$ sesuai dengan perbandingan antara barang yang dihasilkan dengan usaha dan biaya yang dihabiskan. Semakin sedikit tingkat kesulitan, semakin besar tarif zakat. Karakteristik ini membuat zakat bersifat market-friendly sehingga tidak akan mengganggu iklim usaha dan motivasi produksi perusahaan (Wibisono, 2015:13).

Firman AllahswtdalamSurah AtTaubah ayat103 yang berbunyi:

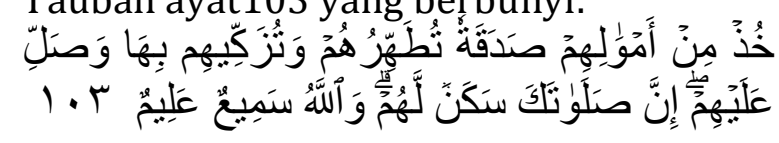

\section{Artinya}

Ambillahzakatdarihartamereka, gunamembersihkan dan mensucikan mereka.Danberdoalah untuk mereka. Sesungguhnya doamu itu (menumbuhkan ketentraman jiwa bagi mereka).AllahMahaMendengar, MahaMengetahui.

Zakat mempunyai pengaruh yang signifikan dalam mengentaskan kemiskinan. Akan tetapi, sesungguhnya maksud dan tujuan zakat tidak terbatas pada pengentasan kemiskinan, melainkan memperluas kepemilikan dengan memperbanyak volume kepemilikan dan juga mengubah orangorang miskin menjadi orang yang berkecukupan seumur hidup. Selain itu, zakat dapat merubah dan meningkatkan perekonomian masyarakat kecil, sebagaimana seseorang pedagang yang mampu memiliki toko dan segala hal yang berkaitan dengan pekerjaanya (Sulaiman, 2016:4).

Peran zakat dalam mengentaskan kemiskinan adalah peran yang tidak bisa dipungkiri keberadaanya, baik dalam kehidupan Muslim ataupun dalam kehidupan lainnya. Khalayak umum hanya mengetahui bahwasanya tujuan dari zakat adalah mengentaskan kemiskinan dan juga membantu para fakir miskin, tanpa mengetahui gembarannya secara gamblang. Kenyataanya, zakat dalam pandangan Islam bukanlah satu-satunya cara untuk dapat mengentaskan kemiskinan. Masih banyak cara lain yang masih bisa diupayakan secara individu ataupun pemimpin masyarakat untuk dapat memenuhi dan menutupi kebutuhan seorang fakir dan juga keluarganya, hingga ia tidak perlu lagi bergantung kepada orang lain. Ada nafkah yang dikeluarkan para kerabat yang mampu untuk membantu kerabat lainnya, dan juga ada kas di banyak negara Islam yang dikeluarkan untuk hak atas harta yang dimiliki setelah dikeluarkan zakatnya. Selain itu, juga ada sedekah yang disunnahkan dan banyak lagi yang lainnya. Kesemuanya itu selain adanya kewajiban zakat bertujuan untuk mengetaskan kemiskinan dan juga melepaskan cengkeramannya (Qardawi, 2005:29).

Menurut Yusuf Al-Qaradhawi, zakat juga akan membersihkan dan mengembangkan jiwa muzakki. Pendapat ini disepakati oleh Ibnu 
Taimiyah (nafsu al-mutashaddiq tazku wa maluh yazku). Sehingga diskusi tentang keberkahan zakat tidak sekadar membicarakan pertambahan jumlah harta, tetapi juga terkait dengan bagaimana pengaruhnya terhadap jiwa dan perilaku muzakki(Nasution, 2017:248).

Saat ini telah berkembang zakat penghasilan $\mathrm{di}$ indonesia meskipun zakat penghasilan ini banyak pro dan kontra yang mana sebagian menyetujui dan sebagaiannya lagi tidak, namun demikian ada fatwa dari Majelis Ulama Indonesia (MUI) yang mana, seperti tertuang dalam Fatwa MUI No. 3 Tahun 2003 tentang Zakat Penghasilan tertanggal 7 Juni 2003, yang menyebutkan penghasilan yang wajib dizakati adalah penghasilan bersih (netto). Penghasilan bersih setelah dikeluarkan kebutuhan pokok (al-haajah al-ashliyah), antara lain kebutuhan diri seperti sandang, pangan, papan, kebutuhan, kesehatan, pendidikan termasuk kebutuhan orang yang menjadi tanggungannya. Padahal potensi zakat penghasilan/ profesi ini apabila dilakukan disetiap perusahaan swasta maupun negeri tentu akan meningkatkan keuangan zakat nasional guna memperbaiki ekonomi Islam serta juga ikut meretaskan kemiskinan di setiap daerah. Namun demikian zakat penghasilan ini belum banyak dikenal termasuk salah satu perusahaan swasta di Pekanbaru salah satunya Rumah Sakit Syafira Pekanbaru.

\section{METODE PENELITIAN}

Penelitian inimenggunakan penelitian lapangan (Field Research).Sumber data dalam penelitian ini adalah data primer dan data sekunder. Data primer merupakan data yang secara langsung diperoleh melalui interaksi peneliti dengan objek yang akan diteliti seperti wawancara atau observasi
(Kuncoro, 2009:5). Penelitian ini menggunakan ketentuan slovin dalam menentukan sampel dengan memasukkan ukuran kelonggaran ketidaktelitian karena kesalahan pengambilan sampel yang masih dapat ditoleransi, nilai toleransi ini dinyatakan dalam bentuk persentase, yaitu 5\%.

\section{HASIL DAN PEMBAHASAN Analisa Deskriptif Variabel Knowledge (Pengetahuan)}

Dalam menjalankan penelitian ini, rumusan masalah yang diambil adalah tentang pengetahuan karyawan Rumah Sakit Syafira tentang zakat penghasilan dan potensi zakat penghasilan di Rumah Sakit Syafira Pekanbaru. Adapun variabel yang di teliti pada penelitian ini adalah sebagai berikut:

\section{Pengetahuan Tentang Zakat}

Pengetahuan tentang zakat ini bertujuan agar karyawan/ responden di Rumah Sakit Syafira mengetahui dan menunaikan kedepannya zakat penghasilan ini. Berikut ini ditampilkan tabel pengetahuan tentang zakat oleh karyawan di Rumah Sakit Syafira.

Tabel 1.

Tabel Pengetahuan Tentang Zakat

\begin{tabular}{|l|c|c|}
\hline \multicolumn{1}{|c|}{ Jenis Zakat } & Total & Persentase \\
\hline Zakat Fitrah & 127 & $80 \%$ \\
\hline Zakat Maal & 13 & $8 \%$ \\
\hline $\begin{array}{l}\text { Zakat } \\
\text { Penghasilan }\end{array}$ & 3 & $2 \%$ \\
\hline $\begin{array}{l}\text { Mengetahui } \\
\text { Semuanya }\end{array}$ & 8 & $5 \%$ \\
\hline $\begin{array}{l}\text { Zakat } \\
\text { Pertanian }\end{array}$ & 2 & $1 \%$ \\
\hline $\begin{array}{l}\text { Zakat Fitrah } \\
\text { dan Zakat } \\
\text { Maal }\end{array}$ & 1 & $2 \%$ \\
\hline $\begin{array}{l}\text { Zakat Hewan } \\
\text { Ternak }\end{array}$ & 3 & $1 \%$ \\
\hline $\begin{array}{l}\text { Zakat Fitrah } \\
\text { dan Zakat } \\
\text { Penghasilan }\end{array}$ & 1 & \\
\hline
\end{tabular}




\section{Total}

\section{Sumber: Data Olahan.}

Dari data tabel di atas dapat dilihat pengetahuan karyawan di Rumah Sakit Syafira lebih banyak mengetahui zakat fitrah dan zakat maal/harta, rendahnya pengetahuan karyawan terhadap zakat penghasilan dengan persentase $2 \%$.

\section{Zakat Yang Pernah Dibayarkan}

Untuk mengetahui pengetahuan tentu terlebih dahulu menanyakan zakat apa saya yang pernah dibayarkan oleh karyawan/ responden di penelitian ini. Berikut ini ditampilkan tabel zakat yang pernah dibayarkan oleh karyawan di Rumah Sakit Syafira.

\section{Tabel 2.}

Tabel Zakat Yang Pernah Dibayarkan

\begin{tabular}{|l|c|c|}
\hline \multicolumn{1}{|c|}{ Jenis Zakat } & Total & Persentase \\
\hline Zakat Fitrah & 127 & $80 \%$ \\
\hline Zakat Maal & 12 & $8 \%$ \\
\hline Zakat Penghasilan & 8 & $5 \%$ \\
\hline Zakat Pertanian & 3 & $2 \%$ \\
\hline Tidak Ada & 1 & $1 \%$ \\
\hline $\begin{array}{l}\text { Zakat Fitrah dan } \\
\text { Zakat Penghasilan }\end{array}$ & 7 & $4 \%$ \\
\hline \multicolumn{1}{|c|}{ Total } & 158 & $100 \%$ \\
\hline
\end{tabular}

Sumber: Data Olahan.

Dari data tabel di atas dapat dilihat zakat yang sering dibayarkan oleh karyawan di Rumah Sakit Syafira ialah zakat fitrah dengan persentase $82 \%$ dan zakat maal dengan persentase $9 \%$.

\section{Tempat Pembayaran Zakat}

Tempat pembayaran zakat lebih baiknya dilakukan dilembaga zakat agar tersalurkan dengan baik dan juga lembaga zakat juga memiliki data orangorang yang berhak menerima zakat (mustahik). Berikut ini ditampilkan tabel tempat pembayaran zakat oleh karyawan di Rumah Sakit Syafira.
Tabel 3.

Tabel Tempat Pembayaran Zakat

\begin{tabular}{|l|c|c|}
\hline Pembayan Zakat & Total & Persentase \\
\hline Lembaga Zakat & 65 & $41 \%$ \\
\hline Keluarga Terdekat & 62 & $39 \%$ \\
\hline Tetangga & 28 & $18 \%$ \\
\hline Tidak Ada & 1 & $1 \%$ \\
\hline $\begin{array}{l}\text { Melalui Masjid } \\
\text { Sekitar Tempat } \\
\text { Tinggal }\end{array}$ & 2 & $1 \%$ \\
\hline Total & 158 & $100 \%$ \\
\hline
\end{tabular}

Sumber: Data Olahan.

Dari data tabel di atas dapat dilihat pembayaran zakat yang dilakukan lebih sering di lembaga zakat dengan persentase $41 \%$ yang artinya sudah tersalurkan dengan baik oleh lembaga zakat tersebut.

\section{Pengetahuan Tentang Lembaga Zakat}

Seiring berjalannya waktu tentu banyak lembaga-lembaga zakat baru yang telah berdiri dan juga memberikan kemudahan kepada orang yang ingin membayarkan zakatnya. Berikut ini ditampilkan tabel pengetahaun tentang lembaga zakat oleh karyawan di Rumah Sakit Syafira.

Tabel 4.

Tabel Pengetahuan Tentang Lembaga Zakat

\begin{tabular}{|c|c|c|}
\hline Lembaga Zakat & Total & $\begin{array}{c}\text { Persenta } \\
\text { se }\end{array}$ \\
\hline Baznas & 86 & $54 \%$ \\
\hline Dompet Dhuafa & 37 & $23 \%$ \\
\hline Rumah Zakat & 31 & $20 \%$ \\
\hline $\begin{array}{l}\text { Baznas dan } \\
\text { Dompet Dhuafa }\end{array}$ & 3 & $2 \%$ \\
\hline $\begin{array}{lr}\text { Rumah } & \text { Zakat, } \\
\text { Lazizmu, Baznas } \\
\text { dan izi }\end{array}$ & 1 & $1 \%$ \\
\hline Total & 158 & $100 \%$ \\
\hline
\end{tabular}

Sumber: Data Olahan. 
Dari data tabel di atas dapat dilihat pengetahun karyawan tentang lembaga zakat lebih banyak baznas yang artinya banyak karyawan yang membayarkan zakatnya di Badan Amil Zakat Nasional (BAZNAS)dengan alasan mudah ditemukan dan juga sudah terpercaya dengan persentase $54 \%$ dan dompet dhuafa dengan persentase $37 \%$.

\section{Pengetahuan Zakat Penghasilan}

Zakat penghasilan yang selama ini kita pandang sebelah mata ternyata memiliki efek yang sangat luar biasa bagi ekonomi Islam, serta memiliki dampak positif/ manfaat bagi kaum Muslim dan Muslimin. Berikut ini ditampilkan tabel pengetahuan zakat penghasilan oleh karyawan di Rumah Sakit Syafira.

\section{Tabel 5.}

Tabel Pengetahuan Zakat Penghasilan

\begin{tabular}{|l|c|c|}
\hline Zakat Penghasilan & Total & Persentase \\
\hline Tahu & 36 & $23 \%$ \\
\hline Tidak Tahu & 65 & $41 \%$ \\
\hline $\begin{array}{l}\text { Pernah } \\
\text { Mendengar }\end{array}$ & 57 & $36 \%$ \\
\hline $\begin{array}{l}\text { Responden Isi } \\
\text { Sendiri }\end{array}$ & 0 & $0 \%$ \\
\hline \multicolumn{1}{|c|}{ Total } & 158 & $100 \%$ \\
\hline
\end{tabular}

Sumber: Data Olahan.

Dari data tabel di atas dapat dilihat pengetahuan karyawan tentang zakat penghasilan berjumlah 65 orang yang artinya karyawan di Rumah Sakit Syafira tidak tahu akan adanya zakat penghasilan pada gaji yang diterima setiap bulannya dengan persentase $41 \%$.

\section{Pengetahuan Tentang Nisab Zakat Penghasilan}

Nisab zakat penghasilan banyak yang tidak mengetahuinya yang mana 2,5\% dari penghasilan kita. Berikut ini ditampilkan tabel tentang nisab zakat penghasilan oleh karyawan di Rumah Sakit Syafira.

\section{Tabel 6.}

Tabel Tentang Nisab Zakat

Penghasilan

\begin{tabular}{|l|c|c|}
\hline $\begin{array}{c}\text { Zakat } \\
\text { Penghasilan }\end{array}$ & Total & Persentase \\
\hline Tahu & 41 & $26 \%$ \\
\hline Tidak Tahu & 56 & $35 \%$ \\
\hline $\begin{array}{l}\text { Pernah } \\
\text { Mendengar }\end{array}$ & 61 & $39 \%$ \\
\hline $\begin{array}{l}\text { Responden Isi } \\
\text { Sendiri }\end{array}$ & 0 & $0 \%$ \\
\hline \multicolumn{1}{|c|}{ Total } & 158 & $100 \%$ \\
\hline
\end{tabular}

Sumber: Data Olahan.

Dari data tabel di atas dapat dilihat pengetahuan karyawan tentang nisab zakat penghasilan diangka $39 \%$, yang mana tidak tahu nisab zakat penghasilan tentu akan membingungkan apabila ditanya atau dilakukannya pembayaran zakat penghasilan ini, untuk itu perlu adanya sosialisasi tentang zakat terutama pada zakat penghasilan.

\section{Pengetahuan Hukum Zakat Penghasilan}

Banyak yang tidak mengetahui hukum zakat penghasilan ini, banyak yang bilang hanya sunnah yang berarti tidak wajib, betul akan tetapi sunnah bukan berarti tidak bisa ditinggalkan begitu saya, apalagi sesuatu yang berhungan pada ekonomi umat yang mana terbantu/ mendongkrak ekonomi Islam. Berikut ini ditampilkan tabel hukum zakat penghasilan oleh karyawan di Rumah Sakit Syafira.

Tabel 7.

Tabel Hukum Zakat Penghasilan

\begin{tabular}{|l|c|c|}
\hline $\begin{array}{c}\text { Hukum Zakat } \\
\text { Penghasilan }\end{array}$ & Total & Persentase \\
\hline Wajib & 88 & $56 \%$ \\
\hline Sunnah & 28 & $18 \%$ \\
\hline Tidak Tahu & 41 & $26 \%$ \\
\hline Tidak Wajib & 1 & $0 \%$ \\
\hline \multicolumn{1}{|c|}{ Total } & 158 & $100 \%$ \\
\hline
\end{tabular}

Sumber: Data Olahan. 
Dari data tabel di atas dapat dilihat pengetahuan karyawan di Rumah Sakit Syafira tentang hukum zakat penghasilan dengan persentase $56 \%$ yaitu menjawab wajib.

\section{Pengetahuan Perhitungan Zakat Penghasilan}

Perhitungan dalam membayar zakat tentu berbeda-beda dari zakat fitrah, zakat maal, zakat penghasilan, zakat pertanian, dll. Berikut ini ditampilkan tabel perhitungan zakat penghasilan oleh karyawan di Rumah Sakit Syafira.

Tabel 8.

Tabel Perhitungan Zakat Penghasilan

\begin{tabular}{|c|c|c|}
\hline $\begin{array}{c}\text { Zakat } \\
\text { Penghasilan }\end{array}$ & Total & Persentase \\
\hline Sangat tidak tahu & 6 & $4 \%$ \\
\hline Tahu & 38 & $24 \%$ \\
\hline Tidak tahu & 110 & $70 \%$ \\
\hline Sangat tahu sekali & 4 & $2 \%$ \\
\hline Total & 158 & $100 \%$ \\
\hline
\end{tabular}

Sumber: Data Olahan.

Dari data tabel di atas dapat dilihat pengetahuan karyawan di Rumah Sakit Syafira tentang perhitungan zakat penghasilan adalah tidak tahu dengan persentase $70 \%$, yang mana karyawan biasaya membayarkan zakatnya ketika telah menerima gaji setiap bulannya langsung dibayarkan kepada lembaga zakat.

\section{Pengetahuan Tentang Perintah Allah Swt Dalam Membayar Zakat}

Perintah Allah Swt dalam membayar zakat ada beberapa kali disinggung didalam Al-Qur'an dan hadist yang mana perintah tersebut jangan lupa untuk membayarkan zakat apa bila telah mencapai nisabnya. Berikut ini ditampilkan tabel tentang perintah Allah Swt dalam membayar zakat oleh karyawan di Rumah Sakit Syafira.
Tabel 9.

Tabel Tentang Perintah Allah Swt Dalam Membayar Zakat

\begin{tabular}{|l|c|c|}
\hline $\begin{array}{c}\text { Perintah Allah } \\
\text { SWT }\end{array}$ & Total & Persentase \\
\hline Mengetahui & 151 & $96 \%$ \\
\hline Tidak Tahu & 3 & $2 \%$ \\
\hline $\begin{array}{l}\text { Sangat Tidak } \\
\text { Tahu }\end{array}$ & 0 & $0 \%$ \\
\hline $\begin{array}{l}\text { Pernah } \\
\text { Mendengar }\end{array}$ & 4 & $2 \%$ \\
\hline \multicolumn{1}{|c|}{ Total } & 158 & $100 \%$ \\
\hline
\end{tabular}

Sumber: Data Olahan.

Dari data tabel di atas dapat dilihat pengetahuan tentang perintah Allah Swt tentang membayar zakat diangka $96 \%$, yang berarti karyawan di Rumah Sakit Syafira mengetahui perintah Allah dalam membayar zakat, karena melihat pengetahuan tentang zakat penghasilan yang baik juga untuk itu perlu dipertahankan agar kedepannya lebih baik lagi.

\section{Zakat Dapat Mengurangi Angka Kemiskinan}

Kemiskinan memang menjadi ancaman setiap negara didunia dan juga tidak terlepas juga dari sumber daya manusia yang ada didalamnya untuk itu pajak juga sebagai bentuk mengurangi angka kemiskinan yang melanda setiap negara, akan tetapi tidak dengan zakat yang memiliki peran penting dalam mengentaskan kemiskinan yang dilakukan oleh umat Muslim dan disaluarkan oleh lembaga zakat dalam bentuk sembako ataupun uang yang mana bisa dimanfaatkan guna mendongkarak ekonomi umaat. Berikut ini ditampilkan tabel zakat dapat mengurangi angka kemiskiann oleh karyawan di Rumah Sakit Syafira. 
Tabel 10.

Tabel Zakat Dapat Mengurangi Angka Kemiskinan

\begin{tabular}{|l|c|c|}
\hline \multicolumn{1}{|c|}{ Zakat } & Total & Persentase \\
\hline Sangat Setuju & 113 & $72 \%$ \\
\hline Setuju & 44 & $28 \%$ \\
\hline Tidak Setuju & 1 & $0 \%$ \\
\hline $\begin{array}{l}\text { Sangat Tidak } \\
\text { Setuju }\end{array}$ & 0 & $0 \%$ \\
\hline \multicolumn{1}{|c|}{ Total } & 158 & $100 \%$ \\
\hline
\end{tabular}

Sumber: Data Olahan.

Dari data tabel di atas dapat dilihat karyawan di Rumah Sakit Syafira sangat setuju bahwa membayar zakat dapat mengurangi angka kemiskinan terutama didaerah tempat dibayarkannya zakat tersebut. Tentu akan terasa pada jangka panjang dan menjadi amal jariyah dengan persentase $72 \%$.

\section{Analisa Deskriptif Variabel Potency (Potensi)}

Secara umum pengertian potensi adalah sebuah kemampuan dasar yang dimiliki manusia yang sangat mungkin untuk dikembangkan, sehingga pada intinya potensi sendiri berarti suatu kemampuan yang masih bisa dikembangkan menjadi lebih baik lagi. Dari segi ekonomi potensi juga bisa merubah ekonomi lebih baik begitu pula dengan potensi zakat dalam membangun ekonomi islam. Untuk mengetahui potensi zakat penghasilan di Rumah Sakit Syafira peneliti sudah memiliki data guna mengetahui potesi zakat penghasilan tersebut. Berikut diagram range gaji pada karyawan di Rumah Sakit Syafira dalam proses penelitian.

\section{Gambar 1.Range Gaji Karyawan}

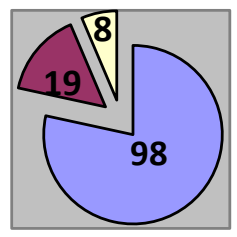

$\square$ Rp. 3.000.000 -

Rp. 4.000.000

$\square$ Rp. 4.000.000 -

Rp. 5.000.000
Zakat penghasilan atau yang dikenal juga sebagai zakat profesi; zakat pendapatan adalah bagian dari zakat mal yang wajib dikeluarkan atas harta yang berasal dari pendapatan / penghasilan rutin dari pekerjaan yang tidak melanggar syariah. Nisab zakat penghasilan sebesar 85 gram emas per tahun. Kadar zakat penghasilan senilai 2,5\%.

Dalam praktiknya, zakat penghasilan dapat ditunaikan setiap bulan dengan nilai nisab perbulannya adalah setara dengan nilai seperduabelas dari 85 gram emas (mengikuti harga Buy Back emas pada hari dimana zakat akan ditunaikan), dengan kadar 2,5\%. Jadi apabila penghasilan setiap bulan telah melebihi nilai nisab bulanan, maka wajib dikeluarkan zakatnya sebesar 2,5\% dari penghasilannya tersebut. Dengan penjelasan di atas dapat diambil range gaji karyawan dengan range gaji $\mathrm{Rp}$. 5.000.000 keatas.

\section{SIMPULAN}

Berdasarkan analisa data yang telah dilakukan dan pembahasan yang telah dijelaskan pada babsebelumnya, dapat ditarik beberapa kesimpulan dari penelitian ini adalah:

1. Hasil penelitian membuktikan bahwa variabel knowledge (pengetahuan) karyawan terhadap zakat penghasilan dibilang cukup, karena kurangnya sosialisasi tentang zakat penghasilan sehingga membuat karyawan di Rumah Sakit Syafira kurang mengetahuinya dan cendrung ke zakat fitrah yang dilakukan setiap tahun.

2. Hasil penelitian membuktikan bahwa variabel potency (potensi) zakat di Rumah Sakit Syafira dengan total Rp. 12.000.000, bisa dibilang cukup baik, untuk itu perlu adanya kerja sama antara Lembaga Zakat dan Rumah Sakit dalam penyaluran 
zakat karyawan di Rumah Sakit Syafira Pekanbaru.

\section{DAFTAR RUJUKAN}

Nasution, J. (2017). Analisis pengaruh kepatuhan membayar zakat terhadap keberkahan. ATTAWASSUTH: Jurnal Ekonomi Islam, 2(2), 282-303.

Qardawi, Yusuf. (2005). Spektrum Zakat Dalam Membangun Ekonomi Kerakyatan, Terjemahan Sari Narulita. Jakarta : Zikrul Hakim.

Sulaiman, Sofyan. (2016). Legalistas Syar'i Zakat Profesi. Jurnal Syari'ah, 5 (1), 1-28.

Wibisono, Yusuf. (2015). Mengelola Zakat Indonesia Diskusi Pengelolaan Zakat Nasioanl dari Rezim UndangUndang Nomor 38 Tahun 1999 ke Rezim Undang-Undang Nomor 23 Tahun 2011. Jakarta:

Prenadamedia Group. 